\title{
Preferences for heat, cold, or contrast in
with knee osteoarthritis affect treatment response
}

\author{
Craig R Denegar \\ Devon R Dougherty \\ Jacob E Friedman \\ Maureen E Schimizzi \\ James E Clark \\ Brett A Comstock \\ William J Kraemer \\ Human Performance Laboratory \\ and Physical Therapy Program, \\ Department of Kinesiology, \\ University of Connecticut, Storrs, \\ CT, USA
}

This article was published in the following Dove Press journal:

Clinical Interventions in Aging

17 July 2010

Number of times this article has been viewed
Objective: This investigation assessed preferences for, and effects of, 5 days of twice daily superficial heat, cold, or contrast therapy applied with a commercially available system permitting the circulation of water through a wrap-around garment, use of an electric heating pad, or rest for patients with level II-IV osteoarthritis (OA) of the knee.

Methods: We employed a within subject, randomized order design to study 34 patients receiving each treatment in 1-week blocks. A knee injury and osteoarthritis outcome score (KOOS) questionnaire and visual analog pain scale was completed at baseline, and twice each week. Treatment preferences were assessed in the last week of the study.

Results: Treatment with the device set to warm was preferred by $48 \%$ of subjects. Near equal preferences were observed for cold (24\%) and contrast (24\%). Pain reduction and improvements in KOOS subscale measures were demonstrated for each treatment but responses were $(P<0.05)$ greater with preferred treatments. Most patients preferred treatment with the water circulating garment system over a heating pad.

Conclusions: We recommend that when superficial heat or cold is considered in the management of knee OA that patients experiment to identify the intervention that offers them the greatest relief and that contrast is a treatment option.

Keywords: pain scales, KOOS, therapeutic agents, knee, patient preferences

Osteoarthritis (OA) of the knee is a common and progressive condition. Michael et $\mathrm{al}^{1}$ reported that $6 \%$ of adults suffer from clinically significant knee OA with the prevalence increasing with each decade of life. Lawrence et $\mathrm{al}^{2}$ provided a summary of population based studies which revealed estimates of symptomatic and radiographically confirmed knee OA as high as $16.7 \%{ }^{3}$ for those 45 years and older, with women more affected than men. ${ }^{2} \mathrm{OA}$ results in pain and recurrent swelling and is associated with progressive functional limitations and disability. ${ }^{2}$ Multiple treatment options are available for patients with OA of the knee including the use of superficial heat or cold, transcutaneous electrical nerve stimulation (TENS), oral medications, injection of hyaluronic acid or a corticosteroid, or ultimately knee joint replacement surgery. ${ }^{4-6}$

Unfortunately, knee OA is a progressive disease and not all patients are good candidates for all interventions. Moreover, there are risks and side effects associated with medications and surgery that are not associated with some remedies, such as superficial heat or cold applications. ${ }^{6,7}$ Furthermore, not all treatment options meet with the same results, supporting individualized patient management approaches. The benefits of others such as injections of hyaluronic acid or a corticosteroid do not last indefinitely and must be repeated. ${ }^{8,9}$ The use of lower risk, lower cost interventions that
Correspondence: Craig A Denegar Department of Kinesiology Unit I I I0, 2095 Hillside Road, University of Connecticut, Storrs, CT 06269, USA $\mathrm{Tel}+\mathrm{I}-860-486-0052$

Fax + I-860-486-I I 23

Email craig.denegar@uconn.edu 
are effective in helping patients manage chronic conditions including knee OA, warrant further examination and attention when discussing treatment options or recommending a plan of care.

The periodic application of superficial heat or cold is a relatively safe and low cost treatment that can be recommended in isolation or in combination with other treatments for patients with knee OA. ${ }^{10}$ Contrast therapy involving intervals of heat and cold application within a treatment session offers yet another option in the management of many different musculoskeletal conditions, including knee OA. Few studies are available to demonstrate if either superficial heat, cold, or contrast therapies are of greater benefit. ${ }^{11}$

Despite limited understanding of the response to heat, cold, or contrast modalities in the management of knee OA, the application of superficial heat or cold is very common, often self-initiated, and is considered a component of a "first-line" intervention in the management of knee pain in older adults. ${ }^{4,12}$ Porcheret et al $^{12}$ reported that of 201 older patients with knee pain surveyed, 84\% reported applying superficial heat or cold, and most reported this treatment as a self-initiated intervention. Additionally, Cetin et $\mathrm{al}^{4}$ reported that the use of superficial heat or cold in conjunction with diathermy, TENS or ultrasound led to varying levels of symptom relief and functional improvements in patients with knee OA.

Health care providers are often asked whether heat or cold is better, and how these modalities should be used outside of clinical settings for treatment of knee OA. ${ }^{11}$ Unfortunately, as previously noted, there are no clear answers or recommendations for patients to follow, hence anecdotal recommendations are often based on personal experiences, patient preferences, and previously established clinical training and education. ${ }^{10-15}$

Studying the response to thermal modalities is complicated by the fact that it is not possible to blind subjects or providers to the intervention. Moreover, clinical observations show many patients have experiences with heat and cold applications and express preferences based on these experiences. The first purpose of this Phase I study (subjects were randomized to order but not to a particular treatment with primary focus on treatment preference) was to investigate the preferences of patients with knee OA using a single device that is able to provide multiple treatment options with an identical method of application.

Other factors may also need to be considered in recommending treatments. Impairments of the hand and loss of mobility in the lower extremities may impede an individual's ability to self-apply superficial heat and cold around a peripheral joint. For example, securing an ice pack can be difficult for some patients. Furthermore, wrapping an electric heating pad in place poses risk of burns, especially if peripheral sensation or circulation is compromised. Several commercially available warm and cold-water circulating units offer a means of surrounding a joint with a garment through which temperature controlled water circulates. These garments are wrapped around the joint and held in place with Velcro $^{\text {TM }}$ closures. These garments may offer a safer and more convenient means of applying cold or heat. The second purpose of this investigation was to assess the preferences of patients toward a given treatment option provided by a wrap-around system when compared to use of a standard electric heating pad.

A preferred treatment may or may not yield a better outcome. The third purpose of this investigation was to assess self-reports of patients with level II or greater $\mathrm{OA}^{16}$ for pain, symptoms, function in daily living (FDL) and recreation, and quality of life (QOL), following 5 days of twice daily superficial heat, cold or contrast therapy applied with a wraparound water circulating device, twice daily use of a standard heating pad, or twice daily rest for 20 minutes.

\section{Materials and methods}

Thirty-six subjects, with Kellgren-Lawrence scale ${ }^{16}$ level II or greater $\mathrm{OA}$, as diagnosed by their independent referring physician, were recruited to participate in a study that was approved by the University of Connecticut, Office of Research Compliance, for use of subjects in research. Each provided written informed consent to participate after the risks and benefits of the study were explained to them. Participants were recruited through presentations and posted announcements within a university community and four (two rural and two urban) community senior centers, from June 2008 to December 2009. Enrollment criteria were described and 36 subjects volunteered for the study. A small number ( $<10$ individuals) contacted the investigators via telephone or in person at a senior center to review their suitability for enrollment but did not qualify, most commonly because their knee had not been examined radiographically.

Thirty-four community dwelling subjects, average age of $62 \pm 14$ years, median grade OA = III (23 women, $64.87 \pm 10.67$ years and median grade $\mathrm{OA}=\mathrm{III}$, and $11 \mathrm{men}$, $54.6 \pm 19.91$ years and median grade $\mathrm{OA}=\mathrm{III})$ completed the study; the distribution of severity by gender is reported in Table 1. Two subjects (one woman, one man) were lost due to non-study related medical complications (illness 
Table I Breakdown of gender and severity of osteoarthritis for all subjects $(\mathrm{N}=34)$

\begin{tabular}{lllll}
\hline \% of subject population that is & & & \\
\hline All subjects & Level II OA: $\mathbf{2 6 . 4 \%}$ & Level III OA: $\mathbf{5 2 . 9 \%}$ & Level IV OA: I7.6\% & Level unknown \\
\hline Men: $32 \%(\mathrm{~N}=\mathrm{II})$ & Male: $\mathrm{N}=3$ & Male: $\mathrm{N}=\mathbf{7}$ & Male: $\mathrm{N}=\mathrm{I}$ & Male: $\mathrm{N}=\mathrm{I}$ \\
Women: $68 \%(\mathrm{~N}=23)$ & Female: $\mathrm{N}=6$ & Female: $\mathrm{N}=1 \mathrm{I}$ & Female: $\mathrm{N}=5$ & \\
\hline
\end{tabular}

precluding travel to weekly meetings and elective total hip arthrosplasty due to increasingly severe hip pain respectively) during the course of the study. Neither of these two participants completed more than 2 weeks of treatment for the study. Any potential subject was excluded if they had received either hyaluronic acid or corticosteroid injections to either knee within the past 6 months, or had a history of an adverse reaction to cold application or diminished sensation to heat or cold in the area of the knee. Furthermore, all subjects were advised to not increase the use of nonsteroidal anti-inflammatory medication at any point in time during the study. All subjects were medically cleared for participation by a physician (personal physician or orthopedic surgeon) knowledgeable of the participant's medical history, severity of symptoms from OA and current health status. The physician was asked to grade the severity of OA of the most involved knee on a form describing each level of the Kellgren-Lawrence scale. ${ }^{16}$ All subjects demonstrated the ability to self-apply the water-circulating device and complete the assigned treatments and questionnaires as instructed by members of the research team.

Subjects met with a member of the investigational team for an orientation session in a university laboratory room or a senior center where they regularly attended community activities. The study was described and questions addressed before asking for consent to participate. Once consent was obtained subjects were instructed in how to complete the knee injury and osteoarthritis outcome score (KOOS) self-report questionnaire and $10 \mathrm{~cm}$ visual pain scale. Details regarding the KOOS instrument as well as the process of scoring responses can be found at http://www.koos.nu/. Subjects were then advised as to their first treatment assignment and instructed in the completion of that treatment. Prior to meeting with any potential subjects, the order of treatments was balanced and randomized to eliminate any statistical order effects. Forty different treatment orders were randomly selected from the 120 possible order combinations, and were numbered consecutively. When subjects enrolled, they were assigned to the order from a random draw of numbers corresponding to a treatment option. Subjects were not informed of treatment order, and would learn of their assigned treatment at the beginning of each week of the study.
Each participant completed five treatment protocols including cold, warm, and contrast (alternating cold and warm) with the water circulating system; superficial heat with an electric heating pad, or control (no treatment) of 1 week ( 7 days) duration. The water-circulating device used for this study was the VitalWrap ${ }^{\circledR}$ portable thermal and compression system (VitalWear Inc., San Francisco, CA, USA). This commercially available device offers a convenient means of applying superficial cold, heat, and an option for contrast through a garment wrapped around the knee.

Each treatment protocol consisted of twice-a-day (morning and evening) application of one of the treatment options for 5 consecutive days, followed by 2 days of nontreatment. Each of the twice daily treatments was applied for 20 minutes except for the contrast treatment, which consisted of 4 minutes of warm followed by 2 minutes of cold (the 4 minute by 2 minute cycle of heat, then cold, was repeated 3 times) and concluded with 4 minutes of warm, in a total session of 22 minutes. During the control week of the study, participants sat quietly for 20 minutes each day in a self-determined position of maximal comfort.

Subjects completed the KOOS self-report questionnaire and visual analog pain scale at baseline (at the beginning of the study, prior to any treatment application), and then twice on the 5th and 7th day of each treatment week. The KOOS was selected as the instrument of choice for measuring changes in the patients, since it is a validated exam for response to treatment in individuals with knee OA across a lifespan and regardless of level of activity. ${ }^{17}$ It is an easy-to-use, self-administered survey that provides for a comprehensive examination of five subscales (pain, symptoms, functions, sports and recreational activities, FDL, and QOL) that are of importance to function and independence for many individuals with knee $\mathrm{OA}$.

Following the completion of all five of the treatment protocols, subjects completed a preference for treatment scale and were asked about any adverse events and changes in weekly medication. No subject reported an adverse event and there was no report of a change in any anti-inflammatory or analgesic medications for any week of the study. To assess treatment preference, subjects were asked to rank the treatment options from most preferred through least preferred 
including the nontreatment control week. Subjects were also encouraged to provide comments on their preferences and experiences with each treatment option used during this study.

\section{Statistical analyses}

Prior to the initiation of the study, we calculated the $\mathrm{N}$ size power based on a change of $15 \%$ in median score of the visual pain scale, and determined that there would need to be a population of 30 subjects to obtain the desired power of 0.80 . Pain was selected for consideration since it is of primary concern and offered the best means of judging whether additional investigation might be warranted as a follow-up to learning more regarding treatment preference.

After each week of treatment, subject data collected were tabulated from the day 5 and 7 KOOS questionnaire subscales of pain, symptoms, sports and recreation activities, FDL, and QOL, and the visual analog pain for each treatment, along with baseline and control week scores. Additionally, subject preferences were tabulated to identify subgroups of the sample. These data were used to investigate the relationships between treatment preference and changes in reported pain, and KOOS subscale responses.

Data were analyzed by a member of the research team who had no contact with subjects or the data collection process. Preference data were presented descriptively. Differences in treatment response were analyzed separately for each of the subscales of interest (as the KOOS was not developed to yield a composite score). Pain data from the visual analog scale were also analyzed separately. Responses to treatment for the day 5 measurements were assessed without regard to preference, and then by treatment of preference, via paired T-tests $(P \leq 0.05)$, with Bonferroni correction. Effect sizes for treatment were determined in reference to day 5 control values $\left(\mu_{\text {active }}-\mu_{\text {control }}\right) /\left(\sigma_{\text {active and control }}\right)$ for active treatments. As a follow-up, KOOS and visual analog pain data were also analyzed to identify differences between treatment days 5 and 7 in each treatment option, via a within-subject repeated measure analysis of variance, $(P \leq 0.05)$.

\section{Results}

As shown in Table 2, participants reported a range of individual preferences for treatment setting. More participants preferred the warm treatment condition, but nearly one-half preferred either cold or the contrast treatment. Most (32 of 34) preferred treatment with the water-circulating device compared to the use of a standard heating pad or no treatment. Regardless of the preference, there were, on average, significant $(P<0.05)$ improvements in pain, symptoms, FDL and QOL KOOS subscale measures with the water circulating device treatment options, (see Tables 3 and 4), when compared with baseline and control week measurements. Twice daily rest (control treatment) resulted in improvements over baseline measures, and therefore the control week data served as our means for comparison with all active treatment options. The extent of improvement in pain and symptoms was often more pronounced when subjects utilized their preferred treatment versus their nonpreferred treatment (Tables 3 and 4).

Data on the function, sport and recreational activities subscale were analyzed, as were data from the other subscales, but are not reported in table form. There was high variability in the responses to the subscale questionnaire. Of the 34 subjects that completed the study, five female subjects, all who preferred the warm treatment (three with OA level of III and two with OA level of IV), reported a 0 of 100 on this subscale at all measurements, and two males who showed preference toward either warm or contrast treatments (OA level II) reported a 100 out of 100 on the subscale at the baseline. Thus, analysis of changes was limited to 27 subjects. Analysis of variance within this remaining group indicated a nonsignificant change in the function, sport, and recreational activities subscale with all treatment options, $(P>0.168)$ and change scores ranging from 0 to \pm 67 points.

Responses similar to the KOOS data were noted in the visual analog pain assessment data, where greater relief was obtained when subjects used their preferred treatment (Table 5). Relief on the pain scale is reported as a positive percentage of improvement. Interestingly, the pattern of similarity between the KOOS pain and visual analog pain data did

Table 2 Breakdown of treatment preferences for all subjects $(N=34)$

\begin{tabular}{lll}
\hline Overall preference $(\mathbf{N}=\mathbf{3 4})$ & & \\
\hline $\begin{array}{l}\text { Most preferred treatment } \\
\text { (\% of population) }\end{array}$ & $\begin{array}{l}\text { 2nd most preferred treatment } \\
\text { (\% of population) }\end{array}$ & $\begin{array}{l}\text { 3rd most preferred treatment } \\
\text { (\% of population) }\end{array}$ \\
\hline Warm (47\%) & Warm $(36 \%)$ & Contrast $(42 \%)$ \\
Cold $(24 \%)$ & Cold $(26 \%)$ & Cold $(29 \%)$ \\
Contrast $(24 \%)$ & Contrast $(21 \%)$ & Hot pad $(18 \%)$ \\
Hot pad $(5 \%)$ & Hot pad $(17 \%)$ & Warm $(11 \%)$ \\
\hline
\end{tabular}


Table 3 Table of the group average \pm standard deviation of the magnitude of change for the measures of the KOOS scale (0-100) for pain and symptoms from the baseline measure for the indicated treatment option on the water-circulating device for the entire group, and then for the subgroups of subjects based on preference

\begin{tabular}{|c|c|c|c|c|c|}
\hline & $\begin{array}{l}\text { Change in KOOS } \\
\text { scale after control } \\
\text { treatment }\end{array}$ & $\begin{array}{l}\text { Change in KOOS } \\
\text { scale after cold } \\
\text { treatment }\end{array}$ & $\begin{array}{l}\text { Change in KOOS } \\
\text { scale after contrast } \\
\text { treatment }\end{array}$ & $\begin{array}{l}\text { Change in KOOS } \\
\text { scale after warm } \\
\text { treatment }\end{array}$ & $\begin{array}{l}\text { Change in KOOS } \\
\text { scale after hot } \\
\text { pad treatment }\end{array}$ \\
\hline \multicolumn{6}{|l|}{ KOOS-pain } \\
\hline Average for all subjects & $1.1 \pm 16.6$ & $5.6 \pm 15.4^{\mathrm{a}}$ & $7.0 \pm 16.7^{\mathrm{a}}$ & $7.0 \pm 17.4^{a}$ & $4.2 \pm 14.9$ \\
\hline $\begin{array}{l}\text { Average for prefer cold } \\
\text { treatment }\end{array}$ & $-6.7 \pm 11.9$ & $0.1 \pm 14.6$ & $-0.4 \pm 10.6$ & $5.9 \pm 14.5^{a}$ & $4.7 \pm 17.4$ \\
\hline $\begin{array}{l}\text { Average for prefer } \\
\text { contrast treatment }\end{array}$ & $-0.2 \pm 10.7$ & $1.74 \pm 14.6^{\mathrm{a}}$ & $8.9 \pm 16.9^{a}$ & $6.2 \pm 18.2^{\mathrm{a}}$ & $2.8 \pm 9.3$ \\
\hline $\begin{array}{l}\text { Average for prefer } \\
\text { warm treatment }\end{array}$ & $4.1 \pm 19.6$ & $6.4 \pm 16.8$ & $9.3 \pm 18.9$ & $6.8 \pm 19.9$ & $3.2 \pm 16.2$ \\
\hline \multicolumn{6}{|l|}{ KOOS-symptom } \\
\hline Average for all subjects & $0.5 \pm 14.0$ & $6.1 \pm 15.2^{\mathrm{a}}$ & $7.5 \pm 15.9^{\mathrm{a}}$ & $6.7 \pm 15.6^{\mathrm{a}}$ & $5.3 \pm 15.7^{\mathrm{a}}$ \\
\hline $\begin{array}{l}\text { Average for prefer cold } \\
\text { treatment }\end{array}$ & $-2.1 \pm 20.4$ & $5.8 \pm 19.4^{a}$ & $3.4 \pm 17 .\left.\right|^{a}$ & $12.1 \pm 19.9^{a}$ & $9.6 \pm 21.5^{a}$ \\
\hline $\begin{array}{l}\text { Average for prefer } \\
\text { contrast treatment }\end{array}$ & $-0.4 \pm 10.6$ & $9.6 \pm 12.4^{a}$ & $7.9 \pm 11.2^{\mathrm{a}}$ & $5.4 \pm 12.7^{a}$ & $0.1 \pm 11.8$ \\
\hline $\begin{array}{l}\text { Average for prefer } \\
\text { warm treatment }\end{array}$ & $1.3 \pm 2.6$ & $3.3 \pm 15.2$ & $9.3 \pm 18.5$ & $3.2 \pm 14.7$ & $4.6 \pm 14.6$ \\
\hline
\end{tabular}

Notes: andicates values of change significant from change after control, T-test $P<0.05$.

Abbreviation: KOOS, knee injury and osteoarthritis outcome score.

not extend to the responses of the group that preferred the warm treatment. In this group, the greatest average change in the visual analog scale was seen following the contrast treatment (see Table 5). Similar to the changes in the KOOS subscales, the effect size estimates ranging from 0.68 to 1.12 , was greatest when individuals used their preferred treatment versus all other treatment options.

Interestingly, nonsignificant differences were found between day 5 and day 7 reports. This nonsignificant difference $(P>0.56)$ was found across all treatment options for

Table 4 Table of the group average \pm standard deviation of the magnitude of change for the measures of the KOOS scale (0-100) for FDL and QOL from the baseline measure for the indicated treatment option on the water-circulating device for the entire group and then for the subgroups of subjects based on preference

\begin{tabular}{|c|c|c|c|c|c|}
\hline & $\begin{array}{l}\text { Change in KOOS } \\
\text { scale after control } \\
\text { treatment }\end{array}$ & $\begin{array}{l}\text { Change in KOOS } \\
\text { scale after cold } \\
\text { treatment }\end{array}$ & $\begin{array}{l}\text { Change in KOOS } \\
\text { scale after contrast } \\
\text { treatment }\end{array}$ & $\begin{array}{l}\text { Change in KOOS } \\
\text { scale after warm } \\
\text { treatment }\end{array}$ & $\begin{array}{l}\text { Change in KOOS } \\
\text { scale after hot } \\
\text { pad treatment }\end{array}$ \\
\hline \multicolumn{6}{|l|}{ KOOS-FDL } \\
\hline Average for all subjects & $-0.1 \pm 15.5$ & $6.1 \pm 16.1^{\mathrm{a}}$ & $6.6 \pm 16.0^{a}$ & $7.2 \pm 15.6^{\mathrm{a}}$ & $4.2 \pm 15.1^{\mathrm{a}}$ \\
\hline $\begin{array}{l}\text { Average for prefer } \\
\text { cold treatment }\end{array}$ & $-7.5 \pm 17.2$ & $3.3 \pm 22.3$ & $4.4 \pm 20.6$ & $8.7 \pm 18.4$ & $0.3 \pm 17.9$ \\
\hline $\begin{array}{l}\text { Average for prefer } \\
\text { contrast treatment }\end{array}$ & $4.5 \pm 5.8$ & $8.2 \pm 17.7^{b}$ & $8.0 \pm 15.5$ & $4.8 \pm 15.6$ & $-1.8 \pm 17.2$ \\
\hline $\begin{array}{l}\text { Average for prefer } \\
\text { warm treatment } \\
\text { KOOS-QOL }\end{array}$ & $4.1 \pm 17.9$ & $7.7 \pm 15.6$ & $8.4 \pm 16.3$ & $8.1 \pm 17.2$ & $7.4 \pm 14.1$ \\
\hline Average for all subjects & $3.3 \pm 12.6$ & $8.0 \pm 14.9^{a}$ & $9.1 \pm 14.4^{a}$ & $9.0 \pm 16.2^{\mathrm{a}}$ & $9.0 \pm 14.0^{\mathrm{a}}$ \\
\hline $\begin{array}{l}\text { Average for prefer } \\
\text { cold treatment }\end{array}$ & $5.9 \pm 18.8$ & $10.1 \pm 8.7^{\mathrm{a}}$ & $9.9 \pm 7.4^{\mathrm{a}}$ & $13.9 \pm 14.0^{\mathrm{a}}$ & $15.9 \pm 13.8^{\mathrm{a}}$ \\
\hline $\begin{array}{l}\text { Average for prefer } \\
\text { contrast treatment }\end{array}$ & $-2.0 \pm 11.3$ & $7.7 \pm 16.3^{b}$ & $6.5 \pm 14.7^{\mathrm{a}, \mathrm{b}}$ & $4.5 \pm 5.2$ & $0.9 \pm 15.4$ \\
\hline $\begin{array}{l}\text { Average for prefer } \\
\text { warm treatment }\end{array}$ & $0.5 \pm 10.7$ & $7.3 \pm 18.2$ & $8.9 \pm 17.6$ & $8.1 \pm 19.1^{a}$ & $8.3 \pm 13.7$ \\
\hline
\end{tabular}

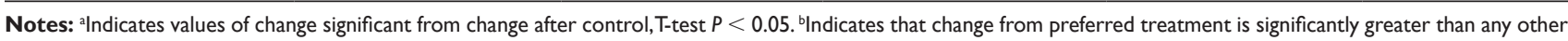
treatment option, T-test $P<0.05$.

Abbreviations: KOOS, knee injury and osteoarthritis outcome score; FDL, function in daily living and recreation; QOL, quality of life. 
Table 5 Table of the group average, \pm standard deviation, percent change of improvement, (treatment measure-baseline measure)/ baseline measure, $(0-1.0)$ for the measures on $10 \mathrm{~cm}$ visual pain scale from the baseline measure for the indicated treatment option on the water-circulating device for all subjects and the subgroups of subjects based on preferences, gender and severity of osteoarthritis pain

\begin{tabular}{|c|c|c|c|c|c|}
\hline & $\begin{array}{l}\% \text { Change in } \\
10 \mathrm{~cm} \text { visual } \\
\text { analog scale after } \\
\text { control treatment }\end{array}$ & $\begin{array}{l}\% \text { Change in } \\
10 \mathrm{~cm} \text { visual } \\
\text { analog scale after } \\
\text { cold treatment }\end{array}$ & $\begin{array}{l}\% \text { Change in } \\
10 \mathrm{~cm} \text { visual } \\
\text { analog scale after } \\
\text { warm treatment }\end{array}$ & $\begin{array}{l}\% \text { Change in } \\
10 \mathrm{~cm} \text { visual } \\
\text { analog scale after } \\
\text { contrast treatment }\end{array}$ & $\begin{array}{l}\% \text { Change in } \\
10 \mathrm{~cm} \text { visual } \\
\text { analog scale after } \\
\text { hot pad treatment }\end{array}$ \\
\hline Average for all subjects & $0.04 \pm 0.50$ & $0.15 \pm 0.25^{\mathrm{a}}$ & $0.21 \pm 0.24^{\mathrm{a}}$ & $0.19 \pm 0.26^{\mathrm{a}}$ & $0.15 \pm 0.25^{\mathrm{a}}$ \\
\hline $\begin{array}{l}\text { Average for prefer cold } \\
\text { treatment }\end{array}$ & $0.00 \pm 0.36$ & $0.33 \pm 0.18^{a, b}$ & $0.22 \pm 0.18^{a}$ & $0.19 \pm 0.22^{\mathrm{a}}$ & $0.20 \pm 0.26^{\mathrm{a}}$ \\
\hline $\begin{array}{l}\text { Average for prefer } \\
\text { contrast treatment }\end{array}$ & $0.00 \pm 0.14$ & $0.09 \pm 0.34^{a}$ & $0.29 \pm 0.25^{\mathrm{a}, \mathrm{b}}$ & $0.11 \pm 0.27^{\mathrm{a}}$ & $0.08 \pm 0.26^{\mathrm{a}}$ \\
\hline $\begin{array}{l}\text { Average for prefer } \\
\text { warm treatment }\end{array}$ & $-0.08 \pm 0.72$ & $0.03 \pm 0.20^{\mathrm{a}}$ & $0.23 \pm 0.18^{a}$ & $0.20 \pm 0.22^{\mathrm{a}}$ & $0.08 \pm 0.26^{\mathrm{a}}$ \\
\hline
\end{tabular}

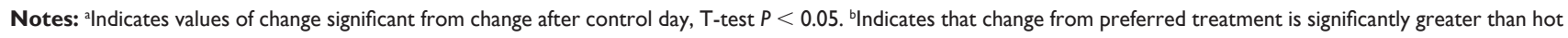
pad treatment option, T-test $P<0.05$.

all points of interest for all subjects. This finding suggests that changes in these measures may persist for a period of 48 hours after 5 days of continuous intervention.

\section{Discussion}

These findings demonstrate that participants with knee OA have individual preferences with regard to the use of heat, cold, or contrast to relieve pain and foster greater motor function. It is also apparent that the use of a wrap-around garment that allows temperature-controlled water to heat or cool is much preferred over a standard heating pad. The reasons for preferences to heat, cold, or contrast require additional investigation, but gender, age, and severity of $\mathrm{OA}$ are all likely to play some role. Women most often preferred treatment providing warmth, while men were more likely to choose cold or contrast as their preferred choices of treatment. Although more women were included in our study, the gender distribution was similar to that of the Bjordal et al, ${ }^{5}$ Zhang et $\mathrm{al},{ }^{6}$ and Tubach et $\mathrm{l}^{19}$ reports, and reflects a gender difference in disease prevalence.

On the whole, all of the active treatments resulted in improvement in all measures of interest (see Tables 3 and 4). These findings must be viewed within the context of the research design. First, we recognize that it is not possible to blind patients to treatment when applying thermal modalities. Moreover, the opportunity to use a novel treatment device may have influenced the responses provided by these patients. However, use of a water circulating device permitted us to learn what treatments (heat, cold, or contrast) these patients preferred using a single application method, and to begin examining the relationships between preference and self-report of pain and function in patients with clinically significant knee OA.
We believe that the average magnitude of change reported on the KOOS and visual pain scale is sufficient to warrant further attention. Tubach et al ${ }^{19}$ reported that a $32 \%$ relative change in pain represented a minimal clinically important improvement and corresponded to a "fair" response in patients with knee and hip OA treated with nonsteroidal anti-inflammatory drugs (NSAIDs). When preferred treatments of cold and warm were used, the patients in this sample reported a mean pain reduction of $33 \%$ and $23 \%$ respectively. It is unknown what longer-term use might yield, but some patients can achieve meaningful relief through these interventions that persist for at least 2 days, with little risk. Responses also fell within the range of clinically important difference as reported by Roos,${ }^{17}$ and correspond to the percent change in the pain (see Table 5) in individual studies of the response to NSAIDs $^{4,5}$ and nonsurgical treatment options ${ }^{5}$ for individuals with knee OA. The effect size for change in pain with use of the preferred treatment was larger $(44 \%-48 \%)$ than the nonpreferred treatment options $(16 \%-36 \%)$ when the watercirculating device was used. Bjordal et $\mathrm{al}^{5}$ reported the effect size for change in pain associated with the use of NSAIDs of $23 \%$ when nonresponders to medication were included in the analysis. We observed, especially in patients with more severe OA, that none of the treatments greatly changed the outcomes measures, however we do not believe this sample is sufficient for subgroup analysis of responders.

While not the primary purpose of this project, the findings related to contrast treatment are quite interesting from a clinical perspective. When preferred, contrast treatment provided at least a two-fold difference to the next closest response to any of the other treatment options, in the percent change of the visual pain scale. While described in therapeutic modality texts, ${ }^{14,15}$ contrast treatment has not been 
extensively studied, especially in patient populations. Hing et $\mathrm{al}^{13}$ completed a systematic review of contrast treatment and concluded that there is insufficient evidence to draw conclusions about this form of therapy. More importantly all of the randomized controlled clinical trials included in their report involved active athletes and college-aged patients, making generalizations to older and diseased populations problematic.

Moreover, the outcome measures reported were of little clinical interest, with the exception of measures of swelling following acute ankle sprain in college-aged patients. ${ }^{18}$ Thus, our findings may be the first report to address measures of contrast therapy treatment outcomes that are truly meaningful to patients in a non-college aged or athletic populations.

Contrast treatment provided the greatest improvement in two of the four KOOS subscales, and was far superior for improving subjects' pain rating via a visual pain scale. This finding is quite surprising given that the contrast treatment was not the most preferred treatment. However, some subjects noted that having to manually change from a warm setting to a cold setting at specific intervals of time as a prime reason for not preferring contrast. If the responses to contrast treatment we observed are substantiated through additional investigation, the use of an automatic timer to switch settings might change patient perception.

Despite the exploratory nature of this study, our findings have implications for clinicians as well as patients. Rather than recommending that a patient specifically use heat or cold, we suggest that patients be advised to experiment with heat, cold, and if possible contrast, to identify their individual preference for treatment, and/or under which condition(s) they experience the greatest relief of pain or symptoms. It is also possible that patients may find that their preference changes under differing circumstances. Several subjects noted that their symptoms fluctuated with variations in activity, and in some cases, the weather. Once again, individual experimentation may yield greater relief under specific circumstances in a safe and relatively costeffective manner.

\section{Conclusion}

In summary, we observed distinctly individual preferences for the use of heat, cold and contrast in patients with knee OA. A preference for treatment with a wrap-around garment over the use of a standard heating pad was also observed. In general, greater pain relief and functional improvements were found when subjects used their treatment of preference. These data support the recommendation that superficial heat or cold be included in the early efforts to manage patients with knee OA, and demonstrate that contrast be considered as a treatment option. We acknowledge that this is a preliminary investigation into the preferences of patients with knee OA to treatments. Heat and cold applications are noninvasive, generally safe, and low cost treatments. It is recommended that future avenues of research include the use of clinical assessments of functionality, eg, the 6-minute walk test, stand-and-walk test, or step test, along with a longer period of treatment to assess both the role of preference for self-directed, in-home care, and possible functional outcomes for patients. It is, we believe, apparent that patient preference must be considered in the development of future investigations.

\section{Acknowledgment}

Supported by a grant from: VitalWear Inc., 384 Oyster Point Blvd, Suite 16, South San Francisco, CA 94080, USA

\section{Disclosure}

None of the authors have a financial or business interest in VitalWear Inc.

\section{References}

1. Michael JW, Schluter-Brust KU, Eysel P. The epidemiology, etiology, diagnosis, and treatment of osteoarthritis of the knee. Dtsch Arztbel Int. 2010;107(9):152-162.

2. Lawrence RC, Felson DT, Helmick CG, et al. Estimates of the prevalence of arthritis and other rheumatic conditions in the United States. Part II. Arthritis Rheum. 2008;58(1):26-35.

3. Jordan JM, Helmick CG, Renner JB, et al. Prevalence of knee symptoms and radiographic and symptomatic knee osteoarthritis in AfricanAmericans and Caucasians: the Johnston County Osteoarthritis Project. J Rheumatol. 2007;34:172-180.

4. Cetin N, Aytar A, Atalay A, Akman MN. Comparing hot pack, short-wave diathermy, ultrasound, and TENS on isokinetic strength, pain, and functional status of women with osteoarthritis knees: a single-blind, randomized, controlled trial. Am J Phys Med Rehabil. 2008;87(6):443-451.

5. Bjordal JM, Ljunggren AE, Klovning A, Slordal L. Nonsteroidal antiinflammatory drugs, including cyclo-oxgenase- 2 inhibitors, in osteoarthritic knee pain: meta-analysis of randomized placebo controlled trials. BMJ. 2004;329(7478):1317.

6. Zhang W, Moskowitz RQ, Nuki G, et al. OARSI recommendations for the management of hip and knee osteoarthritis, Part I: Critical appraisal of existing treatment guidelines and systematic review of current research evidence. Osteoarthritis Cartilage. 2007;15(9):981-1000.

7. SooHoo NF, Lieberman JR, Ko CY, Zingmond DS. Factors predicting complication rates following total knee replacement. J Bone Joint Surg Am. 2006;88(3):480-485.

8. Lo GH, LaValley M, McAlindon T, Felson DT. Intrarticular hyaluronic acid in treatment of knee osteoarthritis: a meta-analysis. $J$ Am Med Assoc. 2003;290(23):3115-3121.

9. Bellamy N, Campbell J, Robinson V, et al. Intraarticular corticosteroid for treatment of osteoarthritis of the Knee. The Cochrane Library (Oxford). 2005;4:CD005328.

10. Oosterveid FG, Rasker JJ. Treating arthritis with locally applied heat or cold. Semin Arthritis Rheum. 1994;24(2):82-90. 
11. Brosseau L, Yonge KA, Robinson V, et al. Thermotherapy for treatment of osteoarthritis. Cochrane Database Syst Rev. 2003;(4): CDO04522.

12. Porcheret M, Jordan K, Jinks C, Croft P. Primary care treatment of knee pain: a survey in older adults. Rheumatology. 2007;46:1694-1700.

13. Hing WA, White SG, Bouaaphone A, Lee P. Contrast therapy a systematic review. Phys Ther Sport. 2008;9:148-161.

14. Cameron MH. Hydrotherapy. In: Physical Agents in Rehabilitation. 3rd ed. St Louis: Saunders Elsevier; 2009;257:269-270.

15. Denegar CR, Saliba E, Saliba S. Cold and superficial heat. In: Therapeutic Modalities for Musculoskeletal Injuries. Champaign IL: Human Kinetics; 2010;122-123.
16. Kellgren JH, Lawrence JS. Radiological assessment of osteo-arthrosis. Ann Rheum Dis. 1957;16(4):494-502.

17. Roos EM, Lohmander LS. The Knee injury and Osteoarthritis Outcome Score (KOOS): from joint injury to osteoarthritis. Health Qual Life Outcomes. 2003;3:1-64.

18. Cote D, Prentice W, Hooker D, Shields E. Comparison of three treatment procedures for minimizing ankle sprain swelling. Phys Ther. 1988;68:1072-1076.

19. Tubach F, Ravaud P, Baron G, et al. Evaluation of clinically relevant changes in patient reported outcomes in knee and hip osteoarthritis: the minimal clinically important improvement. Ann Rheum Dis. 2005;64: $29-33$.

\section{Publish your work in this journal}

Clinical Interventions in Aging is an international, peer-reviewed journal focusing on evidence-based reports on the value or lack thereof of treatments intended to prevent or delay the onset of maladaptive correlates of aging in human beings. This journal is indexed on PubMed Central, MedLine, the American Chemical Society's 'Chemical
Abstracts Service' (CAS), Scopus and the Elsevier Bibliographic databases. The manuscript management system is completely online and includes a very quick and fair peer-review system, which is all easy to use. Visit http://www.dovepress.com/testimonials.php to read real quotes from published authors.

Submit your manuscript here: http://www.dovepress.com/clinical-interventions-in-aging-journal 